\title{
Research on the Innovation of University Service Regional Economy in the Mode of Government, Industry, University and Research Institute
}

\author{
Xu Zhao, Qi Hu, Chunlei Huang, Xuesong Li \\ LiaoNing ShiHua University \\ FuShun, China \\ E-mail: xiangxinlixuesong@126.com
}

\begin{abstract}
The university depends on the professional level which personnel training and scientific research also depends on the level of professional level. The advantage of professional is the basis of the development of the university, improve the scientific research and technology transfer capacity. Formation of innovation cluster has its own characteristics. University subject construction should continue to promote their field of study. On one hand, the public resources could be fully used to improve the conditions of the disciplines and research and to strengthen the multidisciplinary teams. On the other hand, you can master the business and acknowledge market demand closely, update the construction of their disciplines, and creative talents to provide more needs of society and to develop the university's education and scientific achievements into the positive interaction.
\end{abstract}

Keywords-subject construction; Transformation of scientific and technological; Collaborative Innovation

\section{ChANGES IN THE FUNCTION OF UNIVERSITY DisCIPLINE CONSTRUCTION}

More than 30 years of reform and opening up in our country is the history of the pioneering and enterprising innovation. In recent years, government, enterprises and the community devote to promote independent innovation. Research and development spending growth rate remains at $20 \%$ high level, exceeding Japan rise to the second in the world; the total number of R\&D staff is 3.2 million, which is the highest in the world. The social resource allocation tends to the independent research and development, providing a strong support to improve the ability of independent innovation in China. However, Conversion rate of scientific and technological achievements in the developed countries has been more than $70 \%$. China is only about $10 \%$, which is a large number of scientific and technological achievements are "sleeping" in the laboratory, causing a huge waste [1].

The function of the university is the duty of a particular social task and the corresponding function. The university is

1 Ruiai Chen. Collaborative innovation system of building political rese arch,[EB/OL].http://www.npc.gov.cn/npc/zgrdzz/2015-09/16/content_194672 7.htm. determined by the nature and the social division of labor, it not only reflects the essential features of universities also reflects the characteristics of the times. With the development of history and the changing of the times, the University in the whole human society is developing and changing. University plays an important role in the development of the University and the change of times.

A. The function of university discipline construction in the era of agricultural economy

In the agricultural economy, the main mode of economic development is self - sufficiency. Human society is dominated by agriculture and handicraft industry, the whole society is still in a relatively closed state. Because of the knowledge update is slow, long cycle flow and use of the society to the knowledge utilization rate is low, did not show the essence of productivity of science and technology. Therefore, the University placed in a marginalized position in the whole society, less social demand for college, university major contribution to society is the dissemination of knowledge. Including training research and personnel of political, religious and cultural aspects, the university has become the research park, known as "ivory tower". By the middle of the nineteenth Century, many great scientists had come to their knowledge of science, despite the precedents of Boyle and Newton, and science did not root in older universities.[2]

Scholars usually take the interests of scholars to study the direction of the subject, and consciously apply the relevant knowledge of natural to artificial nature, and promote the development of artificial natural activities. In addition to the impact of mathematics by Descartes thought to have a seat in the extraterrestrial University, scientific research and other subjects have no place in the University, new scientific knowledge can enter university courses[3].

\section{B. The function of university discipline construction in the era} of industrial economy

After the Industrial Revolution, the demand for science and technology has greatly increased, and the whole society has produced the worship of knowledge and technology increasingly. Through knowledge transfer, the knowledge and technology transfer from university to economy is the 
embodiment of the social function of university service[4]. At this stage, with the rapid development of artificial nature, natural knowledge of the university is very important. Society needs a large number of scientific talents, to put scientific application into the transformation of artificial natural technology. Therefore, the function of university transfers the traditional research into artificial research.

\section{The function of university discipline construction in the era of knowledge economy}

With the development of knowledge economy represented by information technology, the original connotation of the functions of the University and the content of the functions of the university are also constantly enriched. First of all, University improves the abilities on quality and quantity of cultivating talents; technological innovation and social aspects also have a prominent performance. According to the survey of the National Science Foundation(NSF) in 1980s, the United States has $70 \%$ important technical innovation is produced from basic research, and $60 \%$ basic research is conducted at the University . [5]Secondly, with the emergence of new social and economic conditions, the University also has a number of new functions. At this stage of university curriculum beyond any previous stage, set up a number of social needs and closely relate disciplines. But in the rapid supply of resources under the condition of knowledge economy, the social demand changes rapidly, although the university disciplines settings strive to close contact with the market and social demand, because can not always dynamic understanding of the needs of society the construction of university discipline development, there is a certain lag. As some scholars believe that higher education gradually develop into the economic and social, to provide services for industrial production, but also to participate in social activities, and stay at the edge of the economic and social.[6]

\section{The functions of university discipline construction in the integration of production}

The emergence of cooperation plays the traditional roles on the university of Important Changes have taken place, Universities and enterprises constitute an important part of the industrial chain of the university science and technology city. Become a natural part of the industry. University no longer free from the production exists independently, and part of the industrial nature.

The highest form of production-study-research cooperation: university scientific and technology city makes the university discipline construction into a closer link between the transformation of scientific and technological achievements. Former British the prime minister lady Mrs. Thatcher once pointed out: "historically, the university only played two effects, one is teaching next generation how to think The other is to put forward new ideas, and created a new theory. But the former university did not promote new ideas, new theories, and new promotion. The third function is established the scientific and technology city, the promotion of new ideas in college new discoveries to social and business, make it become the wealth of the whole society."[7] The establishment of university scientific and technological city is not only a continuation of previous artificial natural promote industrial development pattern, the establishment of the more important is through the industry nature, promote the development of the humanized nature and artificial nature, and realize the many resources of close cooperation and complementary relationship.

University and scientific and technological field are the "academic" engine for scientific and technological city, through the cooperation with enterprises, University promote the science and technology achievements transformation and industrialization, achieve the commercialization of scientific research achievements, obtain economic benefits, supplemented by funds and scientific research, and cultivate the scientific research and innovative talents. Enterprises obtain the technology and talents, make use of modern enterprise management experience, provide funds, develop the market development, and promote the development of local economy and employment. Founded by high-tech zone government, by creating good environment and supporting services make resources for effective configuration; make the regional economic development and enhancing the competition ability of comprehensive effect. In short, the three yuan participation theory theoretically explain the dynamical mechanism of the development of science and technology park, universities, enterprises and government is three common participation, coordinate with each other.

\section{SUPPORT OF UNIVERSITY DISCIPLINE TO THE COOPERATION of PRODUCTION, RESEARCH AND RESEARCH}

University or university cluster is the backing of "industry-university-institute" to realize integration of its research and development innovation, enterprise incubation and personnel training, and other functions of reliable protection. Production-study-research cooperation development should take the advantage of university disciplines as the carrier, strengthening scientific research and technology transfer capacity, characteristic of high-tech industry development, innovation cluster has its own characteristics

\section{A. The subject construction of university is important factor of transformation of scientific and technological achievements}

The Stanford Research Park are able to succeed, and gradually becomes today's Silicon Valley. One of the important reason is that research park relies on the support of Stanford University, a high level of disciplines. Stanford University Vice-President Professor Terman proposed "academic cutting-edge" This includes two meanings: one is to attract top talent; the other is to have the conditions of the Department of Sciences into the top academic.[8] Stanford Research Park brings together nearly 100 microelectronics, computers, bio-engineering, chemical and pharmaceutical companies in high-tech areas Such as integrated circuit system center (CIS) is Stanford university microelectronics technology research and teaching base. The development of 70 $\sim 80 \%$ of the results can be used in the industry. There are many research groups in the IC system center, and many topics are high-tech topics in the forefront of science, such as ultra-miniature computers, new semiconductor machines, and so on. Domestically, Tsinghua University science and 
technology park of Tsinghua Founder, Thunis etc.. The development of the enterprise also benefited from Tsinghua university computer science leading position. Growth and development of NEUSOFT group have also been a solid foundation, software information science at northeastern university for its rapid development towards the domestic leading position laid a solid foundation.

Therefore, in the transformation of scientific and technological achievements in accordance with the technical connotation and content of the project set up a corresponding. Besides, rich multidisciplinary auxiliary task is particularly important in the development of each other. This shall be carried out resources flexible configuration and integration method to form the new research body, not only can make the subject development at the university of new resources, as well as provides technical support and comprehensive integration of interdisciplinary talents.

\section{B. The development of University Science provides the} original resources for the transformation of scientific and technological achievements

Transformation usually provides the basis for the development of the University Material Resources and good returns, so as to enhance the construction of the university. University also provides the transformation of scientific and technological achievements, however, the material resources and intellectual resources and influence of its inherent resource, such as library, laboratory, and innovative talents of science and technology and so on. These resources not only directly provide service and technology research, but also enhance the ability to attract other resources for the university, to enhance university to attract capital, technology and talents. Natural resources can be attracted to these resources and join together. They work together to promote scientific and technological achievements transformation and industrialization process.

Second, university of abundant academic resources and human resources, also provide the transformation of scientific and technological achievements of enterprises improve the quality of the talented person's ability to provide the advantageous re-education opportunity, prompting companies always in the forefront of scientific research and innovation, maintaining ability of sustainable development. At the same time, the university can also promote the students to work or internship, to a certain extent; promote the unity of the corporate culture and cohesion, help to form one system of culture.

Anyway, for the University's own development and University Science and Technology City objectives of the good realization the university should follow the change of demand and time combined with their own ability to constantly adjust and optimize the composition of the subject, form the development of the discipline group, inject new vigor and vitality to the development of university. At the same time, also for the transformation of scientific and technological achievements and provide better service level of the integration and closely integrated with social and production levels, increase intelligence security.

\section{TRANSFORMATION OF SCIENTIFIC AND TECHNOLOGICAL ACHIEVEMENTS OF UNIVERSITY DISCIPLINE CONSTRUCTION FEEDBACK FUNCTION}

A. Transformation of scientific and technological achievements promotes the university discipline concise direction

The establishment of the discipline research direction is the direction of the discipline construction, which will lead to the development of other work[9]. This method of scientific research and production practice of cooperative combination, greatly promoting the university form disciplines direction, the development of a new growth point of discipline. There are several aspects of the main:

Firstly, strengthen the development of the University's advantage discipline. The development of University Science and technology industry are conducive to promote the university to serve the economic and social development, and promote the reform and development of the university. But the University Science and technology industry should take the advantage of the school and the talent advantage as the condition, take the talent cultivation as the goal, and combine with the teaching and scientific research, take the high and new technology industry as the main direction. Due to the advantages of the development of science and technology achievements transformation, University tend to focus on certain universities, so the advantages of the university with the development of science and technology achievement transformation and obtained funding and personnel policy support, thus obtained the fast development.

Secondly, a large number of interdisciplinary and emerging disciplines and get a certain development. German physicist Planck once pointed out: "science is the internal unity, it is broken down into a separate department is not due to the nature of things, but because of the limitations of human understanding." Because of the need to meet the needs of social and industrial production, a large number of subjects cross the case, to promote the production of cross disciplines and emerging disciplines.

\section{B. Industrial production of industry university research cooperation promotes the innovation of university discipline}

In the process of the construction of industry university research cooperation, the development of the industry is mainly oriented to the economic interests, so the transformation function of University's scientific and technological achievements is very important. The selection of a number of mature industrial applications based on the original innovation and integrated innovation, as soon as possible to transfer and spread to the enterprise. To build a comprehensive technical team to meet the needs of the operation of the market, as a result of the transformation of scientific and technological achievements in the construction of research universities. From the enterprise's problems and the production needs of the enterprise combination, can make the University of science and technology research to better serve the community, standing in the forefront of the field of service for the people. 


\section{The industrial structure adjustment of industry university research collaboration promotes the discipline construction of University}

University disciplines are also fundamentally a sort of knowledge. In addition to the general characteristics of the subject, but also its own particularity, that is, it is a kind of organizational form of knowledge classification for talent training. The development and structure of discipline have a great relationship, in the process of cooperation, to focus on fostering the development of University of science and technology for the industry, in accordance with the development of appropriate technology industry characteristics and the industrial structure of the university itself, so as to form a new economic growth point. The new industrial structure adjustment and requirement fully play leading role on research universities, based on strengthening the characteristics, advantages, to carry out scientific research development direction actively around the national strategic emerging industries, to enhance the level of scientific research, leading into a new road to industrialization and pioneers, to play a leading role on the birth of the construction of research university. For example, the establishment of the Stanford Research Park not only improves the Stanford University's scientific research ability and level, improve the scientific research of Stanford University, also provide research institutes, laboratories and Research Center for scientific research and technology development activities.

\section{SUMMARY}

The construction and development of industry-university-research cooperation and the teaching mode of university make the learning content of students closely meeting the social demand and, also it enables the research of teacher contributing to the service and market. With the definite guidance, the combination of talent's development and employment practices greatly changed the mode of talent training and clarified the guidance of employment. So, talents' potentials would be fully developed which requires to cultivate student's ability and to start their entrepreneurial idea for research universities. The students' entrepreneurial ability and enthusiasm can be obtained and the actual practice in the cooperation within the relevant content during the period of school students can experience employment, entrepreneurship, accumulated experience provides a rich social experience for the graduate into society. By taking the above measures, construct the research universities with the employment orientation.

\section{REFERENCE}

[1] Samia Mohamed Nour, Overview of Regional Systems of Innovation in the Arab Region, Economic Systems of Innovation in the Arab Region, 2016, pp 167-231.

[2] Susan Kinnear, Kate Charters, Innovation for Regional Advantage: A Reflection, Regional Advantage and Innovation, 2013, pp 403-437.

[3] Yu. A. Fridman, G. N. Rechko, Competitive advantages and innovation in regional economies, Regional Research of Russia, Vol 2, Issue 3, pp 206-213, July 2012.

[4] Jin Hong, Wentao YuEmail author, Xiumei Guo, Dingtao Zhao, Creative industries agglomeration, regional innovation and productivity growth in China, Chinese Geographical Science, Vol 24, pp 258-268, April 2014.

[5] Ugo Fratesi, Regional innovation and competitiveness in a dynamic representation, Journal of Evolutionary Economics, Vole 20, pp 515-552, August 2010.

[6] Jari Kolehmainen, Joe Irvine, Linda Stewart, Zoltan Karacsonyi, Tünde Szabó et al. Quadruple Helix, Innovation and the Knowledge-Based Development: Lessons from Remote, Rural and Less-Favoured Regions, Journal of the Knowledge Economy, Vol 7, pp 23-42, March 2016.

[7] Philip Cooke, The virtues of variety in regional innovation systems and entrepreneurial ecosystems, Journal of Open Innovation: Technology, Market, and Complexity, pp2-13, December 2016.

[8] Sam TavassoliEmail author, Nunzia Carbonara, The role of knowledge variety and intensity for regional innovation, Small Business Economics, Vol 43, pp 493-509, August 2014.

[9] Haifeng Qian, Talent, creativity and regional economic performance: the case of China, The Annals of Regional Science, Vol 45, pp 133 - 156, August 2010. 